\title{
The Commentary Translation of China's International Publicity Documentaries - A Case Study of A Bite of China I
}

\author{
Lan $\mathrm{Li}$ \\ School of Foreign Languages, Yangtze University, China
}

\begin{abstract}
As a particular kind of audio-visual programs, Chinese Documentaries for international publicity, which aims at spreading China's voice and facilitating the understanding of China, have played a significant role in cultural communication. Compared with other translation activities, its translation has some unique features. This paper takes China's culinary culture documentary A Bite of China I as case, through descriptive method, it comes to the following conclusions: in order to achieve better communication through publicity documentaries, the translator should bear in mind the transferring means, purpose, and target audiences. Firstly, such translation can be included in the field of Audio-visual Translation, so the synchronization between image and sound is the first concern; secondly, In order to show the real China and transmit Chinese culture to the fullest extent possible, the translators had better be source-language centered and translate those cultural specific words literally. Thirdly, to form a coherent and cohesive text, the appropriate transformation of thematic progression is an effective way to achieve the naturalness and acceptability of the target language text.
\end{abstract}

Index Terms - commentary, international publicity, documentaries, A Bite of China, thematic progression

\section{INTRODUCTION}

With increasingly frequent communications between countries, the global exchanges of movies and TV programs have greatly enhanced people's understanding of other cultures. In order to make the world know its own culture well, every country makes a great effort to output its excellent cultural achievements. Among all of these output methods, documentary is an important one which can reveal a nation's real characteristics and presents its real image in economy, society, culture, science and technology.

As a particular kind of audio-visual programs, Chinese Documentaries for international publicity, which aims at spreading China's voice and facilitating the understanding of China, have played a significant role in cultural communication. To achieve the expected communicational goal, appropriate transfer of message from Chinese into other languages is the prerequisite. Hence the paper develops its research questions around the translation of documentary commentaries.

A Bite of China I, a Chinese culinary culture documentary with seven episodes, was first launched on China Central Television (CCTV) Documentary Channel in 2012. It quickly gained extensive attention from all walks of life and even caused a scramble among overseas producers over its right. Currently, there are three foreign versions available for the foreign audience on the CCTV official international broadcasting website-CNTV, namely English, France, and Spanish. It is not just a documentary showcasing food from all over China, but a manifestation of the multiple sides of Chinese culture through eating. It is also themed about Chinese way of thinking and changes to people's lives with china's social progress. Naturally a film with such a profound theme makes the translation all the more difficult.

In this paper, the source commentary and the translated English version of A Bite of China I was chosen as the research case. It firstly reviewed relevant literature to sum up the unique characteristics for audio-view translation and special requirements for international publicity translation. Then it attempts to analyze how the translated commentary synchronize picture with voice, while at the same time remain a coherent discourse from the perspective of Thematic Progression Theory with examples. It aims to provide a new research perspective for film and television translation and to attract more researches to this area.

\section{LITERATURE REVIEW}

\section{A. The Translation of Documentaries}

A documentary is defined as a film or television or a radio program that gives detailed information about a particular subject in Longman Dictionary of Contemporary English (2017). It can be regarded as a particular kind of audio-visual product which combines image, sound, and commentary. But unlike other types of films which are usually accompanied with dialogues, a documentary has no continuous dialogues between protagonists, so certain written or spoken commentary to convey the story to the audience is needed. Hence the commentary of documentaries is of great 
importance in that it not only serves as a supplement of the picture as well as an assistant to the understanding of the theme, but a means to attract the audience to its charm.

As the intercultural communication through films and TV programs became more frequent, much attention has been given to the translation of film and television works, generally called audio-visual Translation, or Screen Translation(ST), or Audio Visual Translation, which resulted in the boom in the research of this field. However, generally speaking, although the receivers of translated film and television works are much larger than those of literary works, the research on this field is slightly lacking behind compared with traditional literary translation studies. This is worse in China as most of the related research focuses on the translation from other language into Chinese, few takes the Chinese film and television works as research object, due to the fact that for a long time, more films and TV programs were imported from abroad than those exported to other countries. So it is necessary to explore the translation of Chinese film and television works for the purpose of better communication in the backdrop of globalization. Which is the starting point of this research.

\section{B. International Publicity Translation}

The term "international publicity", "wai xuan" in Chinese, is a term originated from China and boomed with China's opening up to the outside world in recent decades. Chinese scholar Huang Youyi states, in the process of China's consistent social development, a conspicuous demand for in-depth international exchange arises, and therefore, a large amount of information related to China needs to be translated into foreign languages in order to achieve international publicity via media, i.e., books, periodicals, newspaper, broadcast, television, Internet, and international conferences (Huang, 2004).

In another scholar Zhang jian's point of view, international publicity translation generally refers to a translation activity in which the source information is initially provided in Chinese, through C-E translation, aiming at helping foreign audiences to be better informed of China via all forms of media (Zhang, 2013).

In a word, international publicity translation is a communicative activity, which aims at spreading China's voice and facilitating the understanding of China. With the increasing of China's comprehensive national strength and its influence on international community, the publicity work of the country is increasingly taken seriously by the state. In the work of international publicity, documentaries are often regarded as one of the most effective means of communication, through which the image of the country and of the people can be shaped with real stories.

Actually, there are two types of translated documentaries. One is with translated subtitles at the bottom of the screen. Another one is with dubbed commentary. And the topic discussed in this paper is the latter. Currently, most scripts of films for international publicity in China are made in Chinese first, and then translated into foreign languages. Those works bear the effort to publicize Chinese society and culture internationally and showcase China's image to the world. Some typical examples include the promotional video for the Olympics in 2001, the promotional film for the World Expo in 2002 and China's national image publicity film in 2011.

\section{Thematic Progression}

The commentary of a documentary can be taken as a text, which, according to Thematic Progression (TP) theory, can be regarded as a sequence of related themes and rhemes. TP, as an important way to realize information transmission and textual coherence, refers to the thematic/rhematic connection of various types. In a coherent discourse, sentences are not freely grouped together and there is a certain law guiding the train of thought. According to Danes, Thematic progression might be viewed as the skeleton of the plot. (Danes: 1974). As Chinese and English belong to different language families, there are distinct requirements in information transmission and textual coherence. The most important difference between English and Chinese could be the contrast between hypotaxis and parataxis in terms of linguistics. Moreover, English falls into the category of subject-prominent language, while Chinese is a topic-prominent language. Hence Chinese relies a lot on topic chains instead of grammatical cohesive devices, discarding all unnecessary accessory elements, in which the ellipsis of themes (or subjects) and the initial position of adverbial clauses are quite frequent. So in the C-E translation, the proper choice and arrangement of themes and rhemes is of crucial importance to the success of textual cohesion.

\section{AUdIO-VISUAL TRANSLATION AND SPECIAL REQUIREMENTS FOR INTERNATIONAL PUBLICITY}

Compared with other translation activities, the translation of China's International Publicity Documentaries has some unique features.

Firstly, a documentary is a particular kind of film. So its translation shares some features of film translation. Most importantly, such requirements like the synchronization between image and sound makes its translating process a constrained activity. For subtitling, such constrains like the 'six second rule' setting the length of time a subtitle will be shown on the screen, require the condensation of the original text sometimes. For dubbing, though not so demanding like lip-synchronizing in films, the translated text has to keep pace with the picture moving and music. So when a new image or picture appear, the appropriate commentary should begin to retain the artistic unity.

Secondly, there are numerous culturally specific elements in the commentary of China's international publicity documentaries, which may block target language audiences' comprehension as well as appreciation. Together with the 
aim of spreading China's voice and facilitating the understanding of China, it is inevitable to put the translator in a dilemma. So how to properly address the cultural default while at same time maintain exotic cultural properties is what they should bear in mind all the time. In order to show the real China, sometimes they have to make bold decision.

Thirdly, in translation, to form a coherent and cohesive text, the selection of themes is not random or groundless, the first clause or clause complex in a text usually contains new information, but the themes of the following clauses are usually not unexpected, which are connected in one way or another with their neighboring theme or rheme. Only by fully grasping the similarities and differences between the two linguistic structures and functions can we truly be able to carry out the transformation of two languages in a fluent and coherent manner. What's more, because the purpose of international publicity translation is to realize cultural transmission, the translated documentary commentary should center on the target language readers, and be close to the target language audience's habits to realize logical consistency.

\section{A Case Study with A Bite of China I}

Generally speaking, China's International Publicity Documentaries are to publicize China on a particular subject through audiovisual means. So in the translation of such materials, the translator should bear in mind the transferring means, purpose, and target. The following will illustrate how the English version of A Bite of China I deal with these unique requirements in its translation.

\section{A. Perfect Synchronization of Picture and Voice}

A Bite of China I was made in Chinese first, and then the translated versions followed. The official English version of it with dubbed commentary, which was carefully and elaborately translated, gained popularity instantly among those Chinese fans.

As we know there are significant differences between English and Chinese in their phonetic structure. In modern Chinese, a syllable is composed by an initial consonant, a simple or compound vowel and tone. Some syllables have no initials like ài 爱 (love). Generally speaking, one Chinese character is composed of one syllable. While in English, a syllable is made up of none, one, or several consonants and a vowel sound or one of the phoneme [m/n/l]. And a word of English can have one, two, three or even more syllables. However, the speech rates of most languages don't very as much as one may think on the basis of subjective perception (Cees: 2002). So sometimes the translated text has to be shorted or lengthened in order to be articulated with similar period of time as the source text. In the audio-visual translation, the translator has to keep the number of syllables of the translated version similar to that of the source text. When articulated they cost similar period of time, thus synchronization was achieved.

Let's have a look at these randomly chosen examples:

1a 中国自然地理的多样变化, 让生活在不同地域的中国人享受到截然不同的丰富主食。从南到北, 变化万千 的精致主食, 不仅提供了人身体所需要的大部分热量, 更影响了中国人对四季循环的感受, 带给中国人丰饶、 健康、充满情趣的生活。

1b The geography of China is very diverse so people living in different areas enjoy different staple foods. Staple foods not only provide calories, they also have a great effect on people's feelings towards the seasons and then enable them to have a happy, healthy and interesting life. In China, tastes in staple foods vary from south to north.

2a 从农耕文明走到工业文明, 技术的进步, 使得粽子不再局限于地域和时令。但是对中国人来说, 顺应自然, 亲手做合适的食物, 更意味着对传统生活方式的某种延续。

$2 \mathrm{~b}$ The arrival of the industrial revolution meant that the production of Zongzi was no longer limited by region or season. But many people feel that making them by hand is a way of preserving part of a natural, traditional lifestyle.

In example 1, altogether there are 96 syllables in the Chinese commentary and 92 in English, which ensured the two versions be broadcasted within about the same period of time, and the synchronization between the picture and the voice, meanwhile made it sound natural to the target language audience. To achieve this, the translator omitted some words like “大部分”, “循环”, “精致”, etc. Meanwhile the original subject in source text “从南到北, 变化万千的精致 主食”, was translated into a separate sentence“In China, tastes in staple foods vary from south to north”.

In example 2, both the source and the target text contain 66 syllables, which is realized mainly by the restructuring and reformulation to the source language, as well as the omission of terms like “农耕文明”. Although certain information is lost during the process, the artistic unity is retained so that when a new image or picture appear, the appropriate commentary begins.

\section{B. Proper Showcase of Exotic Culture}

As a television documentary about Chinese dietary culture, A Bite of China I is full of unique Chinese cultural elements such as the names and cooking procedures of Chinese cuisines, traditional handicrafts/tools and cultural specific ingredients/raw materials, all of which have posed great challenges to its translators. On the one hand, the English-speaking audiences from different cultural backgrounds don't have much Chinese cultural schema stored in their long-term memories. On the other hand, the translated version has to take the responsibility of transmitting the voice of China, which cannot be achieved without the introducing of Chinese-specific element. How the translator deals with this contradiction, let's have a look at the following examples: 
3a 饺子, 粽子, 泡馍, 馕, 包子, 毛豆腐, 乳扇, 豆腐球

3b Jiaozi, Zongzi, Paomo, Nang, Baozi, Fluffy Tofu, Milk fan, and tofu balls

4a 岐山臊子面, 雷山鱼酱, 潮州春卷

4b Qishan Minced Noodles, Leishan Fish Sauce, Chaozhou Spring Roll

$5 \mathrm{a}$ 焖, 烤, 烘, 熏, 灼, 蒸, 煮

$5 \mathrm{~b}$ braise, roast, bake, smoke, scald, steam, and boil

From the above examples, we can see that most Chinese cultural words are translated literally, from the traditional Chinese cuisine as shown in $3 \mathrm{a}$, to local delicacies in $4 \mathrm{a}$, and to Chinese cooking techniques in 5a. In discussing international publicity translation, Chinese scholar Yuan Xiaoning advocates the "Binary Coexistence" method, that is, target language centered in linguistic expression, and source-language oriented with culture-loaded words and expressions for which literal translation method is recommended.(Yuan 2013) In translating such material for cultural publicity, a taste of foreignness can be a way to keep the audience curious. As cultural globalization becomes a tendency, literal translation of cultural elements might be a good way for bettering understanding and cultural enrichment.

With this method, the English version of A Bite of China I made an attempt to transmit Chinese culture to the fullest extent possible.

\section{Appropriate Transformation of Thematic Progression}

Thematic progression gives a comprehensive explanation of themes in a text, and makes the seemingly random theme choice quite well-organized from a textual perspective. As appropriate transformation of thematic progression is an effective way to achieve the naturalness and acceptability of the target language text. Let's take episode 2 as an example to see how the translator choose themes and rhemes in the translation.

6a 地打在侗语里的意思是泉水之源。地处清水江源头的地扪村, 一年中阴雨天居多。 (The meaning of Dimen in Dong dialect means the source of spring in the Dong dialect. Dimen village which is located in the source of Qingshui River has more rainy days)

6b People of the Dong ethnic group live in Dimen village. Dimen means source of the water and it is usually overcast or rainy in Dimen village which is located by the south of Qingshui River.

$7 \mathrm{a}$ 与黎平米粉做法非常相似的是广州人最爱吃的一种米食——河粉, 150 年前在广州沙河一带出现, 于是这种 食物也叫沙河粉。(What resembles the way of making NIping rice noodles is a kind of rice food---River rice noodle, which Guangzhou people like to eat . It was found 150 years ago in the Shahe river in Guangzhou, so it is also called Shahe River rice noodle)

$7 \mathrm{~b}$ Meanwhile in Guangzhou, people are very fond of a similar type of rice noodles coming on in as Shahe rice noodles.

$8 \mathrm{a} 1000$ 多年前, 中国以秦岭、淮河一线划分出南稻北麦的农业分布, 因此造成了南方人爱吃米、北方人则离 不开面食的现象。(1000 years ago, China along the line of Qinling Mountains and Huai River set the South rice North wheat agricultural distribution, resulting in the phenomenon that Peoplevin the south prefer rice but people in the north can live without wheat-based foods.)

$8 \mathrm{~b}$ People in the south prefer rice but people in the north prefer wheat-based foods. The situation has existed for over a thousand years and it"s due to the different regional agricultural conditions.

9a 晚稻成熟之后, 就到了宁波人做年糕的时候。(After the late rice has harvested is the time for people in Ningbo to make rice cakes.)

$9 \mathrm{~b}$ After the late rice has harvested, people in Ningbo begin making rice cakes.

As the title The Story of Staple Foods suggests, this episode is to introduce various kinds of staple foods people in different parts of China enjoy, which are manifested by a series of stories about some real people. In the above examples, $6 \mathrm{a}, 7 \mathrm{a}, 8 \mathrm{a}, 9 \mathrm{a}$ are the first sentence to introduce some isolated story about a different local staple food. While in the source text, themes in each sentence vary, the topic of the description remains the same, namely, Chinese people and their varied staple foods. Unlike Chinese, which is a topic-prominent language, English is a subject-prominent language which , and most of the time the subject serves as the theme, so in the translated English version 6b, 7b, 8b, 9b "people" is chosen as the theme, while not the same ones as in the source language, originally “地打在侗语里的意思”(the meaning of Dimen in Dong dialect), “与黎平米粉做法非常相似的是” (What resembles the way of making NIping rice noodles), “中国以秦岭、淮河一线”(China along the line of Qinling mountains and Huai river), “晚稻成熟之后”(after the late rice has harvested) in the source text. As the theme is the bridge to connect the known information and the new information, the original themes in Chinese are too scattered and may block the continuity of the text if translated literally. So to keep the translated documentary commentary a natural and coherent whole and to facilitate understanding and acceptance among the target language audiences, the translator restructured and transformed the sentence and arrange them according to the target themantic progression pattern.

In sum, in order to achieve better communicative effects as well as a qualified translated version, the translator should bear both the intentions of the original text and the expectations of the target audience in mind.

\section{CONCLusion}


With increasingly frequent communications between countries, the global exchanges of movies and TV programs have greatly enhanced people's understanding of other cultures. As a particular kind of audio-visual programs, Chinese Documentaries for international publicity, which aims at spreading China's voice and facilitating the understanding of China, have played a significant role in cultural communication. Compared with other translation activities, its translation has some unique features. This paper takes China's culinary culture documentary A Bite of China I as case, through descriptive method, it explores how the translated version turned out to be a natural accompaniment to the image. It comes to the following conclusions: China's International Publicity Documentaries are to publicize China, so in the translation of such materials, the translator should bear in mind the transferring means, purpose, and target. Firstly, its translation can be included in the field of Audio-visual Translation, so the synchronization between image and sound is the first concern; secondly, In order to show the real China and transmit Chinese culture to the fullest extent possible, the translators had better be source-language centered and translate those cultural specific words literally. Thirdly, to form a coherent and cohesive text, appropriate transformation of thematic progression is an effective way to achieve the naturalness and acceptability of the target language text.

\section{REFERENCES}

[1] Danes, F. (1974). Functional sentence perspective and the organization of the text. F. Danes, ed. Papers on Functional Sentence Persepctive (106-128). Prague: Academia /The Hague: Mouton.

[2] Huang, Youyi. (2004). Holding Tightly to Principles of International Publicity Translation and Properly Dealing with the Difficulties. Chinese Translators Journal, 6:27-28.

[3] Longman Dictionary of Contemporary English. http://www.ldoceonline.com/dictionary/secession (accessed 20/9/2017).

[4] Cees M. Koolstra, Allerd L. Peeters and Herman Spinhof. (2002). The Pros and Cons of Dubbing and Subtitling European Journal of Intercultural Communication, 3: 325-354

[5] Yuan Xiaoling. (2013). Binary Coexistence, the Strategies for International Publicity Translation, Chinese Translators Journal 1: 93-97.

[6] Zhang, Jian. (2013). Discussions on Alternative C-E International Publicity Translation Strategies in the Context of Globalization. Foreign Languages and Literature, 1:20-30.

Lan Li was born in Enshi, China in 1975.She received her master's degree from Yangtze University, China in 2008. She is currently an associate professor at the School of Foreign Studies, Yangtze University, Jingzhou, china. Her research interests include Translation Studies, Foreign Language Teaching and Research. 